\title{
Treatment of postoperative distal anastomotic endoleak with the Amplatzer Vascular Plug II in chronic aortic arch dissection: A case report
}

\author{
Iskander Bouassida, MD, ${ }^{a}$ Olivier Meyrignac, $\mathrm{MD},{ }^{a}$ Bertrand Marcheix, $\mathrm{MD}, \mathrm{PhD},{ }^{\mathrm{b}}$ \\ Paul Revel-Mouroz, MD, ${ }^{\mathrm{a}}$ and Hervé Rousseau, $\mathrm{MD}, \mathrm{PhD},{ }^{\mathrm{a}}$ Toulouse, France
}

\author{
From the ${ }^{\mathrm{a}}$ Radiology Department and ${ }^{\mathrm{b}}$ Vascular Surgery Department, CHU Rangueil, Toulouse, France. \\ Disclosures: Authors have nothing to disclose with regard to commercial support. \\ Received for publication April 28, 2017; revisions received June 28, 2017; accepted for publication July 30, 2017; \\ available ahead of print Sept 13, 2017. \\ Address for reprints: Iskander Bouassida, MD, Radiology Department, CHU Rangueil, 1 Ave du Professeur Jean \\ Poulhès, 31059 Toulouse, France (E-mail: iskander.bouassida@gmail.com). \\ J Thorac Cardiovasc Surg 2018;155:e7-10 \\ $0022-5223 / \$ 36.00$ \\ Copyright (c) 2017 by The American Association for Thoracic Surgery \\ http://dx.doi.org/10.1016/j.jtcvs.2017.07.081
}

Video clip is available online.

Surgical reintervention is the reference technique for treating anastomotic leak at the distal anastomosis after aortic ascending replacement for acute aortic dissection. Reoperation, however, is considered to carry high per procedure risks. We present here the case of a patient who underwent treatment of anastomotic leak in chronic aortic arch dissection with the Amplatzer Vascular Plug II (AVP II; St Jude Medical, St Paul, Minn).

\section{CLINICAL SUMMARY}

A 65-year-old patient was admitted to the emergency department of our institution 10 years ago for an acute type A aortic dissection. Consequently, he underwent an ascending aorta replacement with a supracoronary Dacron polyester fabric tube.

Two years later, computed tomographic follow-up demonstrated a large reentry of the left subclavian artery. Moreover, the reentry led to an aneurysmal evolution of the patent false lumen from the aortic arch $(48 \times 45 \mathrm{~mm})$ to the left common iliac artery. Because our patient had severe comorbidities, the surgical approach was discarded, and he underwent an endovascular procedure.

The diagnostic aortography confirmed delayed antegrade opacification of the false lumen originating from the dissected left subclavian artery. A $10 \times 40-\mathrm{mm}$ balloonexpandable covered stent (Atrium Medical Corp, Merrimack, NH) was placed in the true lumen of the left subclavian artery through a $7 \mathrm{~F}$ right femoral introducer (Figure 1, $A$ and $B$ ).

The control aortography revealed persistent delayed antegrade opacification of the descending aorta false lumen,

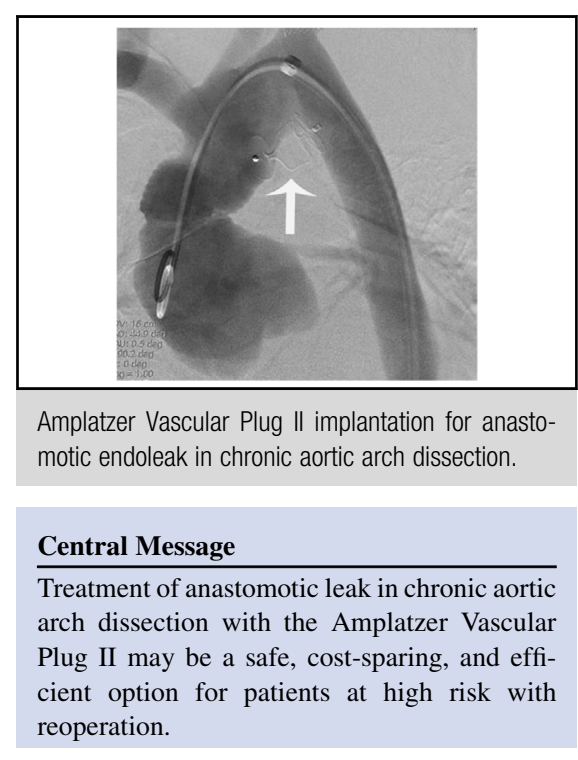

See Editorial Commentary page e11.

however, despite correct left subclavian artery stent placement. We therefore catheterized the false lumen from a reentry of the common iliac artery up to the arch with a vertebral catheter. There the angiography demonstrated an entry tear at the Dacron polyester fabric tube distal anastomosis (Figure 1, $C$ and $D$ ).

We obtained the exclusion of this anastomotic leak by placing a 14-mm AVP II, which was delivered through the false-lumen approach with the same 7F femoral introducer. We positioned 1 disk in the true lumen and 2 disks in the false lumen to avoid major protrusion. The final aortogram with 3-dimensional C-arm computed tomography demonstrated complete false-lumen exclusion and correct AVP II positioning (Figure 1, D and $E$ ).

Clinically, no adverse event occurred during or after the intervention, allowing our patient to be discharged from the hospital after 24 hours with aspirin as long-term therapy. Annual computed tomographic follow-up demonstrated false-lumen thrombosis at the 1-year follow-up and aortic remodeling at the 7-year follow-up (Figure 2 and Video 1).

\section{DISCUSSION}

Anastomotic leak after aortic ascending replacement for acute aortic dissection at the distal anastomosis implies a 


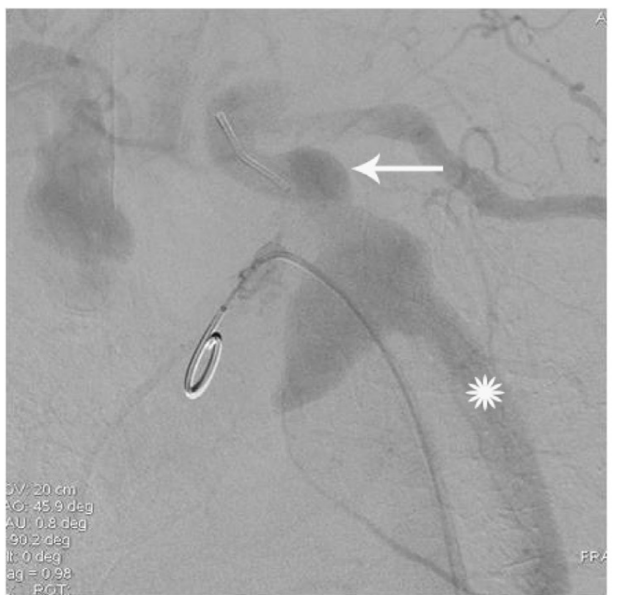

A

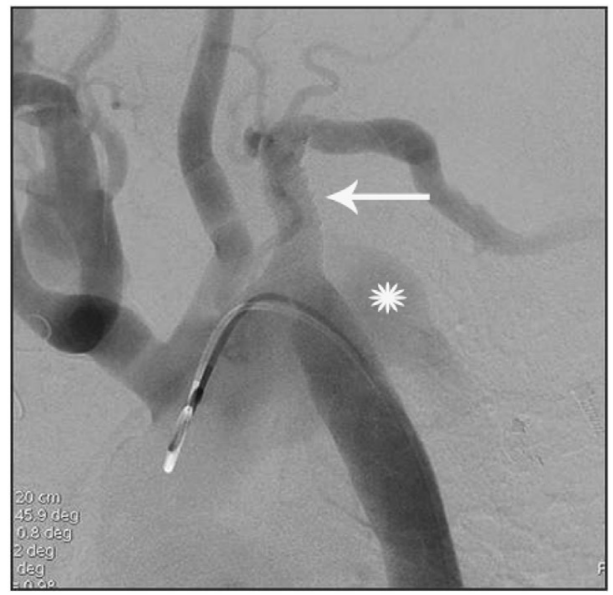

C

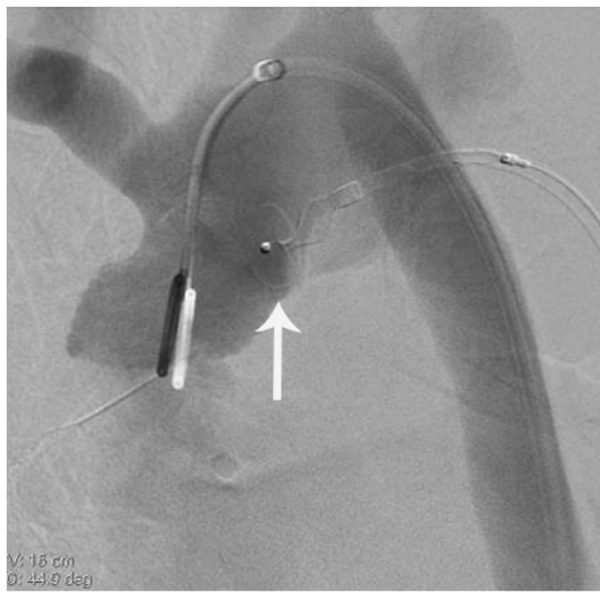

E

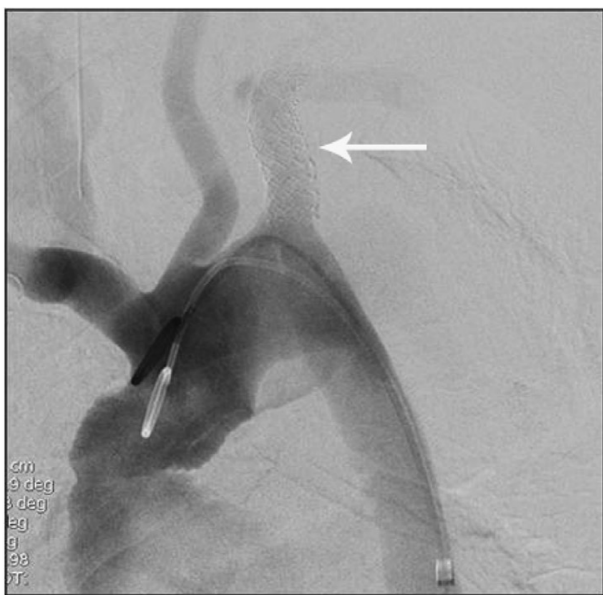

B

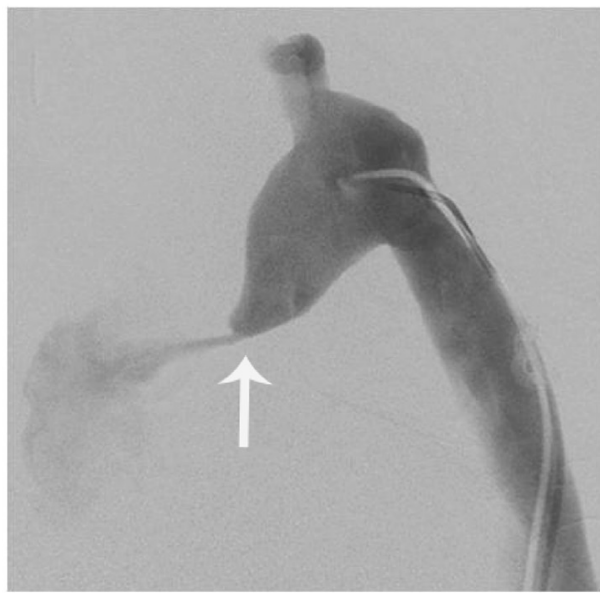

D

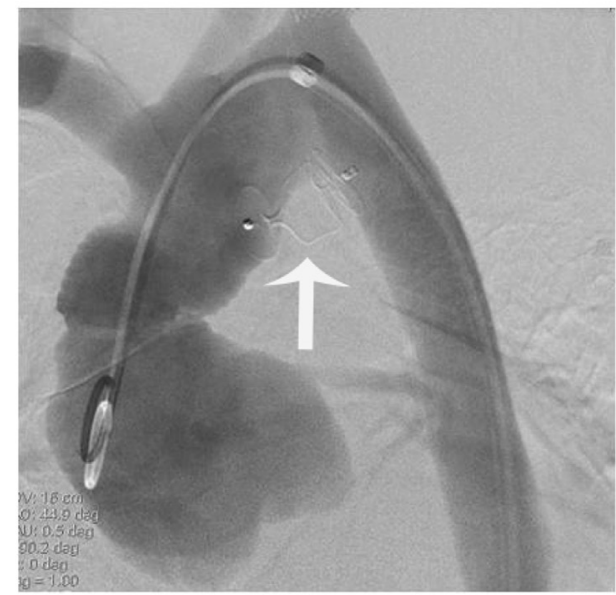

$\mathbf{F}$

FIGURE 1. A-D, Angiography before and after implantation of the Amplatzer Vascular Plug II (St Jude Medical, St Paul, Minn). A, Delayed antegrade false-lumen opacification (asterisk) originating from the dissected left subclavian artery with large reentry from the left subclavian artery (arrow). B, Correct placement in the left subclavian artery (arrow) of a $10 \times 40$-mm balloon-expandable covered stent (Atrium Medical Corp, Merrimack, NH). C, Persistent delayed antegrade false-lumen opacification (asterisk) despite correct stent placement (arrow). D, Angiography from the false lumen shows an entry tear (arrow) at the distal anastomosis of the Dacron polyester fabric tube. E, Implantation of a 14-mm Amplatzer Vascular Plug II through a false-lumen approach. One disk is placed in the true lumen (arrow), with the distal end remaining in the false lumen. F, Aortography after Amplatzer Vascular Plug II implantation (thick arrow) shows no residual false-lumen opacification. 


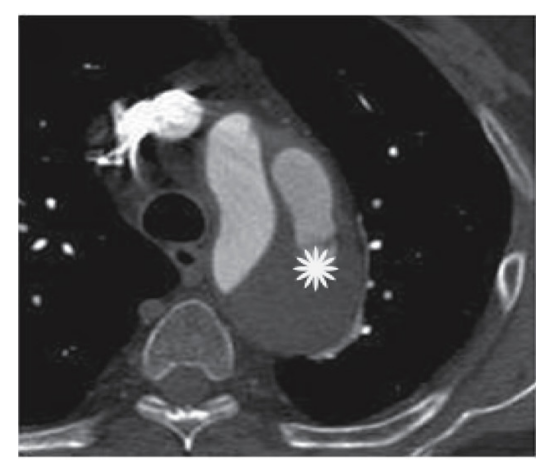

A

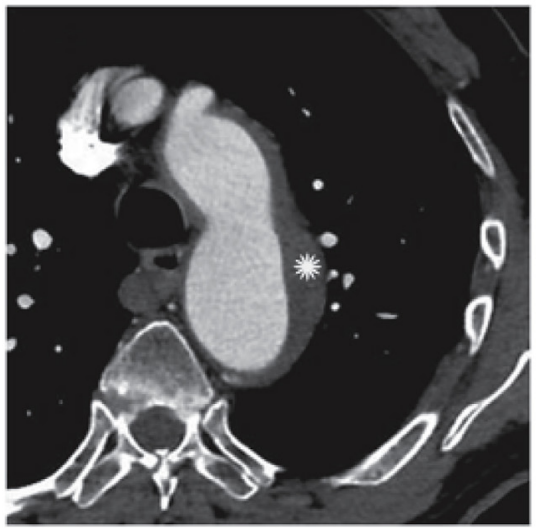

C

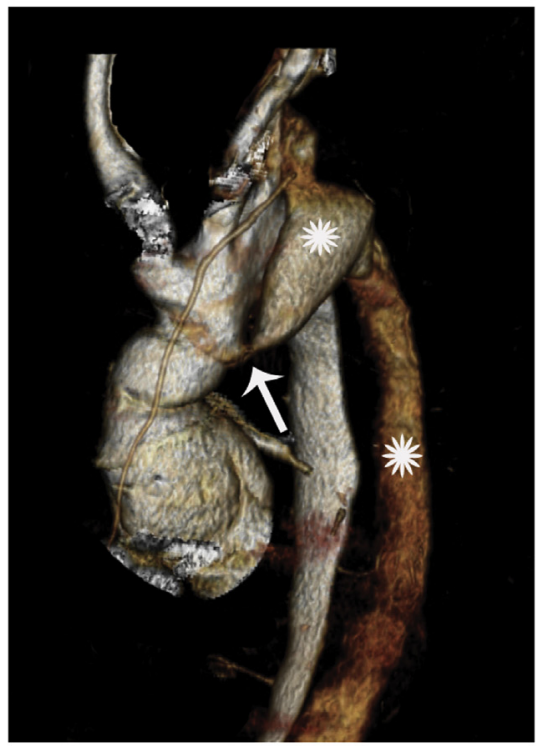

E

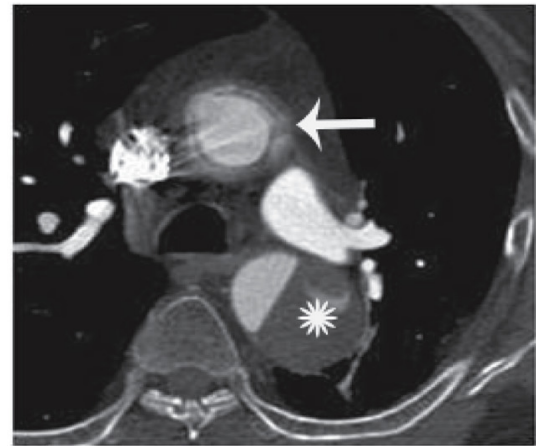

B
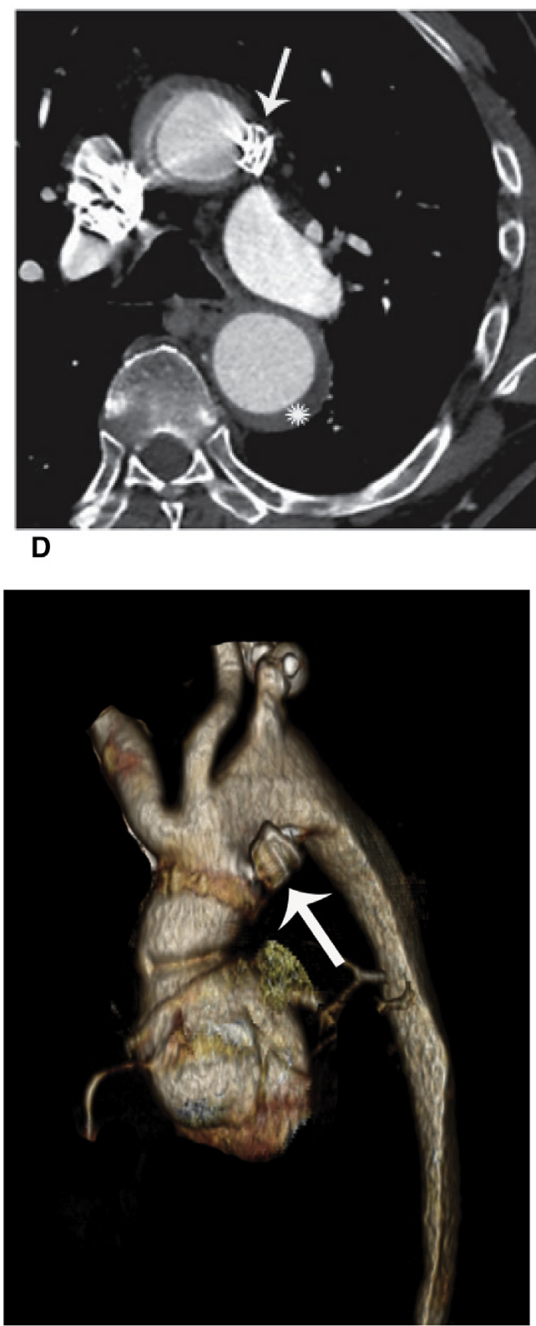

$\mathbf{F}$

FIGURE 2. A-D, Initial computed tomography (A and B) and follow-up computed tomography at 7 years after Amplatzer Vascular Plug II (St Jude Medical, St Paul, Minn) implantation (C and D). E-F, Three-dimensional volume rendering reconstructions of initial computed tomography (E) and computed tomography at 1-year follow-up (F). A, Circulating false lumen (asterisk) with aneurysmal evolution at the aortic arch level (48 $\times 45 \mathrm{~mm})$. B, Ascending thoracic aorta at the Dacron polyester fabric tube distal end $(30 \mathrm{~mm}$; arrow), circulating false lumen, and aneurysmal evolution of the descending aorta $(46 \times 44 \mathrm{~mm}$; asterisk). C, Thrombosed false lumen with aortic remodeling (aortic arch, $46 \times 42 \mathrm{~mm}$; asterisk). D, The Amplatzer Vascular Plug II is positioned without significant protrusion (arrow). Note descending thoracic aorta false lumen thrombosis and remodeling ( $42 \times 40 \mathrm{~mm}$; asterisk). E, Entry tear at the Dacron polyester fabric tube distal anastomosis (arrow). Asterisks indicate circulating false lumen. F, The Amplatzer Vascular Plug II positioned at the entry tear (arrow). Note the absence of circulating false lumen. 


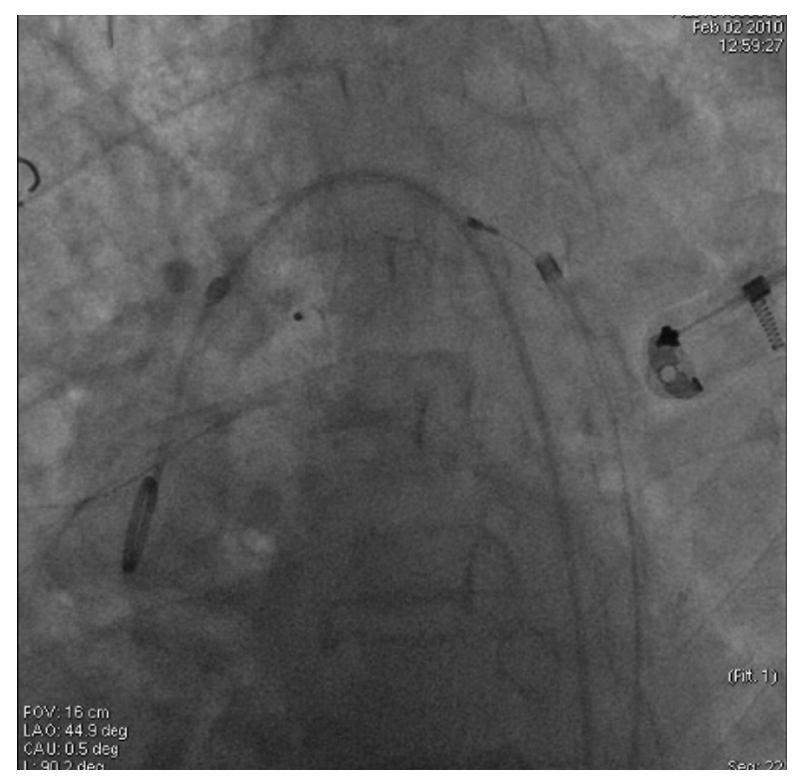

VIDEO 1. A 14-mm Amplatzer Vascular Plug II (St Jude Medical, St Paul, Minn) is delivered through a false-lumen approach: 1 disk is positioned in the true lumen and 2 disks are positioned in the false lumen to avoid major protrusion. Video available at: http://www.jtcvsonline.org/article/S00225223(17)31777-4/fulltext.

direct blood flow forward the false lumen, preventing false lumen thrombosis. False-lumen patency is described as an independent risk factor for distal reintervention because it leads to malperfusion syndromes, aortic aneurysmal evolution, and thus rupture.

Surgical reintervention stands as the reference technique to cure ascending aortic replacement complications, but it is considered to carry the expense of high per procedure risks. Surgical reintervention includes the need for general anesthesia, extracorporeal circulation, and such aggressive surgical techniques as total arch replacement. Although mortality after a conventional or frozen elephant trunk technique remains acceptable, ${ }^{2}$ our patient had pulmonary sarcoidosis with right ventricular dysfunction, and the risk of surgical reintervention was considered to be very high. A less invasive percutaneous endovascular approach under local anesthesia was subsequently chosen, with patient's written consent.

Although the use of endovascular stent grafts has been reported to treat aortic anastomotic leaks, ${ }^{3,4}$ such a technique was not suitable for our patient because of the limitation of the landing zone, with the risk of covering supra-aortic trunks. A customized branched stent graft was not available. ${ }^{5}$ The use of coils has also been described for this condition in treating patients who are not operative candidates ${ }^{6}$; in our case, however, false-lumen patency made the risk of migration high.

Some recent case reports have suggested the utility of the AVP II for treating aortic arch entry sites in chronic dissection. $^{7}$ To our knowledge, this is the first report of the treatment of an ascending anastomotic leak with a plug with a long-term follow up. Introducers of smaller caliber $(6 \mathrm{~F}$ or $7 \mathrm{~F}$ ) than those needed for stent-graft placement are sufficient to deliver the device, reducing complication rates and the length of hospital stay. Moreover, the shape and flexibility of the AVP II allow positioning from the false lumen, leaving the first disk in the true lumen and the distal end of the device in the false lumen. Through this placement, this technique reduces the possibility of device migration in the false lumen thanks to the device fixation by the delivery guidewire, and the risk of thrombus formation in the true lumen is limited because only 1 disk is protruding in the true lumen. Finally, the AVP II seems an efficient closure system with appropriate size selection, leading in our case to persistent false-lumen thrombosis and aortic diameter stability 7 years after its implementation.

In conclusion, treatment of anastomotic leak in chronic aortic arch dissection by AVP II appears to be a fast, safe, cost-sparing, and efficient therapeutic option for patients who would face a very high risk with surgical intervention.

\section{References}

1. Concistrè G, Casali G, Santaniello E, Montalto A, Fiorani B, Dell'Aquila A, et al. Reoperation after surgical correction of acute type A aortic dissection: risk factor analysis. Ann Thorac Surg. 2012;93:450-5.

2. Shrestha M, Haverich A, Martens A. Total aortic arch replacement with the frozen elephant trunk procedure in acute DeBakey type I aortic dissections. Eur J Cardiothorac Surg. 2017;51(Suppl 1):i29-34.

3. Angeli E, Pacini D, Martin-Suarez S, Dell'Amore A, Fattori R, Di Bartolomeo R. Stent repair of aortic perianastomotic leak after aortic arch and descending aorta replacement. Ital Heart J. 2004;5:951-3.

4. Roselli EE, Idrees J, Greenberg RK, Johnston DR, Lytle BW. Endovascular stent grafting for ascending aorta repair in high-risk patients. J Thorac Cardiovasc Surg. 2015;149:144-51.

5. Lu Q, Feng J, Zhou J, Zhao Z, Li H, Teng Z, et al. Endovascular repair by customized branched stent-graft: a promising treatment for chronic aortic dissection involving the arch branches. J Thorac Cardiovasc Surg. 2015;150:1631-8.e5.

6. Nørgaard A, Andersen LI, Haahr PE, Justesen P. Coil embolization of an anastomotic leak after ascending aorta replacement. Acta Radiol. 2008;49:510-2.

7. Kanaoka Y, Ohki T, Ozawa H. Repair of chronic aneurysmal aortic dissection using a stent graft and an Amplatzer ${ }^{\circledR}$ Vascular Plug: a case study. Ann Vasc Surg. 2017;39:288.e5-12. 